THE EFFECTS OF AMYGDALOID STIMUIATION ON PASSIVE AVOIDANCE 


\title{
THE EFFECTS OF AMYGDALOID STIMULATION \\ ON PASSIVE AVOIDANCE
}

\author{
by \\ Louis J. Pellegrino
}

A thesis submitted to the Faculty of Graduate studies and Research in partial fulfillment of the requirements for the degree of Master of Arts.

Department of Psychology

McGill University

Montreal

August 1964 


\section{Table of Contents}

Acknowledgments

Introduction............................

Method.................................

Subjects...........................

Apparatus...........................

Procedure.........................4

Results.............................

General behavior...................6

Mouth shocks.......................

Approach-withdrawals..................8

Latency.........................

Time spent frozen..................8

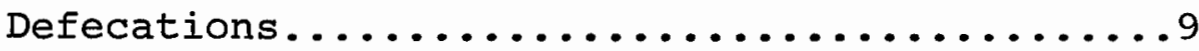

Histology .........................

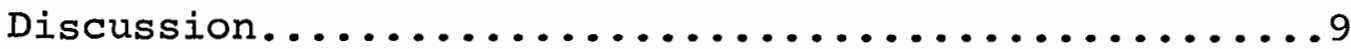

summary..............................14

References............................. 16

Figures................................. 19

Tables............................... 31 
Acknowledgements

I wish to thank Phyllis Kasper for her help with histological techniques and with the design of the experiment; Mr. William Mundl for his technical assistance in the design and construction of the apparatus; James Weiffenbach for his invaluable advice on the statistical treatment of the data; Mrs. Shirley McDonald for her typing of the manuscript. I am most indebted to Ann Shumann for her criticism and suggestions during the preparation of the manuscript. 
Several investigations suggest that the amygdala plays a significant role in behavioral inhibition. Brutkowski, Fonberg and Mempel (1960) reported that bilateral lesions of the amygdaloid complex in dogs severely impaired inhibitory conditioned responses, while excitatory conditioned responses remained unaffected. Bilateral lesions of the amygdala have also been shown to impair the acquisition of the conditioned emotional response (Kellicutt \& Schwartzbaum, 1963), and the retention of an auditory frequency discrimination in a bar pressing situation for food (Schwartzbaum, Thompson \& Kellicutt, 1964). In the latter study, amygdaloid lesioned rats typically persisted in responses that were no longer adaptive, that is, they increased responding under nonreinforced conditions.

Electrical stimulation of the amygdala has been shown to inhibit spontaneous food intake and conditioned alimentary reactions in cats (Fonberg \& Delgado, 1961); attack behavior (Egger \& Flynn, 1962, 1963) and fear reactions (Fonberg, 1963) elicited by hypothalmic stimulation. Noncontingent, continuous stimulation of the amygdala has also been shown to impair the acquisition of a conditioned emotional response (Goddard, 1963). 
Although the role of the septal area in passive avoidance behavior has been clearly demonstrated, very little attention has been given to the function of the amygdala in this type of behavioral inhibition. McCleary (1961) using cats and Kaada, Rasmussen and Kveim (1962) using rats have shown that septal lesioned animals are severely impaired in the acquisition of the passive avoidance response (PAR). A similar impairment in the PAR has been produced by noncontingent, continuous septal stimulation (Kasper, 1963, 1964). Horvath (1963), using cats that had previous training with peripheral shock in a shuttle-box, found that amygdaloid lesions attenuated the acquisition of the passive avoidance response only to a very limited extent.

The purpose of this study was to determine the effects of noncontingent, continuous, low-level amygdaloid stimulation on the acquisition of the passive avoidance response.

Method

Subjects

The Ss were 34 naive male hooded rats obtained from the Quebec Breeding Farm. They were divided into five 
groups: basolateral amygdala placements $(n=5)$; corticomedial amygdala placements $(n=5)$; stimulated controls $(n=8)$; fully operated controls $(n=9)$ and normal controls $(n=7)$. Operated $\underline{s} s$ weighed $250-310 \mathrm{gm}$. at the time of surgery and all Ss weighed 250-300 gm. at the start of testing. Apparatus

The test chamber was an open top, wooden box with a grid floor measuring $13 \times 9.5 \times 16$ in. The front wall of the chamber was clear plexiglass permitting observation during testing. A stainless steel water spout projected from the middle of the left wall, 2 in. from the grid floor.

White masking noise produced by a Grason-Stadler Model 901A noise generator was fed to a 4.5 speaker placed directly behind the test chamber. Brain stimulation, from a Grass Model S4 Stimulator, consisted of biphasic pulses at $100 \mathrm{cps} ., 0.5 \mathrm{msec}$. pulse duration. The current, monitored on a Dumont Fairchild 704 Oscilloscope was kept constant at $20 \mu \mathrm{A}$ for all stimulated animals.

Electrodes consisted of twisted strands of either diamel insulated platinum wire or formvar coated stainless steel wire with a diameter of 0.01 in. soldered to \#27-9 
Amphenol plugs. Electrode holders were \#27-7 Amphenol connectors.

The mouth shock, applied between the water spout and the grid, was supplied by a transformer adjusted to 40 volts by a potentiometer.

\section{$\underline{\text { Procedure }}$}

Surgery. All surgical implantations were performed under Nembutal anesthesia. The animals were held in a Stoelting stereotaxic instrument. Coordinates for electrode placements were A.P.: $0.0 \mathrm{~mm}$. from bregma, L: $5.0 \mathrm{~mm}$. ; $\mathrm{H}: 8.0-9.0 \mathrm{~mm}$. from the skwll. Four small jeweller's screws were screwed into the skull around the electrode. The electrode was held in place by Caulk NuWeld poured around it and the four screws. Following surgery, each $\underline{\mathrm{S}}$ was given an intramuscular injection of approximately 100,000 units of penicillin. All operated $\underline{s}$ s were given a seven day postoperative recovery period, during which they were handled daily.

Test procedure. The test procedure was essentially the same as that used previously by Kasper (1963, 1964) with some minor modifications. Each $\underline{\mathbf{S}}$ was maintained on 23 hour water deprivation during the entire experiment. 
The experiment consisted of seven daily $20 \mathrm{~min}$. sessions. After each session, the $\underline{\text { Ss }}$ were returned to their home cages and after a period of $20 \mathrm{~min}$. were allowed ad lib. water for the following $20 \mathrm{~min}$. Food, in the form of dry lab pellets, was present in the home cages at all times. During the first session the water spout was not electrified and the ss were permitted to drink freely for the full 20 min. During this session, as in all subsequent test sessions, brain stimulation was turned on for all stimulated animals before they were placed in the test chamber.

During each of the six test sessions all $\underline{\text { ss }}$ were allowed to drink freely for the first five minutes, and then the spout was electrified for the remaining $15 \mathrm{~min}$. of the session. Several behavioral measures were recorded during each session. The latency of the first daily contact with the spout, that is, the time from when the animal was placed in the test chamber to when he made his first contact with the water spout, was measured by a stopwatch. The number of mouth shocks, number of approachwithdrawals, number of defecations and time spent frozen were recorded for each animal. 
Histology. After the last test session, the $\underline{\text { s }}$ were perfused and their brains removed and fixed in 10\% formalin. Frozen sections of the electrode tract at $36 \mu$ were mounted and stained with luxol fast blue and neutral red.

Statistical procedure. All differences between groups were evaluated with the large sample form of the Mann-Whitney U Test (Ferguson, 1959). Monotonic trends were determined by nonparametric trend analyses (Ferguson, 1962). All probabilities are two-tailed.

\section{Results}

\section{General Behavior}

The general behavior of $\underline{S} s$ in both the experimental and control groups during the adaptation and test sessions was very similar. All S ss eventually located and drank from the water spout during the adaptation session. On the first test session when the spout was electrified, al1 $\underline{\text { Ss }}$ reacted to the mouth shock by jumping back and freezing momentarily. They then returned to the spout and either made additional attempts to drink, thus receiving more mouth shocks or, made a series of approach-withdrawal responses. Occasional attempts to escape from the chamber were made by $\underline{S} s$ in each group. $\underline{S} s$ in both the amygdala 
groups and the stimulated control group were frequently ebserved to make very quick, jerky movements while walking around the test chamber. The brain stimulation apparently

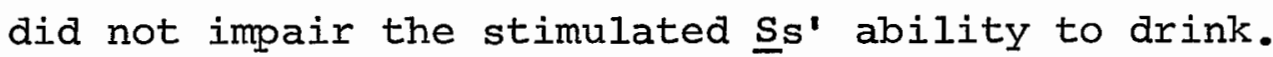
Although the amygdala is very sensitive to seizure activity, seizures were never observed in the animal's behavior during the test sessions at the current intensity (20 $\mu \mathrm{A})$ used. Following the last test session seizures were observed when E raised the current above $50 \mathrm{MA}$. In a previous pilot study in which EEG recordings were used to monitor the stimulation for seizure activity, seizure activity was never recorded at $20 \mu \mathrm{A}$, but was observed at higher intensities.

\section{Mouth Shocks}

Experimental animals (basolateral and corticomedial placements) accepted more mouth shocks (Fig. 1) than each of the control groups (p<.001). Table 1 summarizes the difference between groups on all the measures. There was no difference between the basolateral and corticomedial S s (Fig. 2) with the exception of the last day ( $p=.02)$. The only significant monotonic trends were those of each of the control groups (pr.001). This type of trend is 
to be expected as the control $\underline{\text { ss }}$ learn to inhibit the relevant approach response.

Approach-Withdrawals

Experimental Ss made more approach-withdrawal responses (Fig. 3) than either operated controls (p<.05) or normal controls $(\underline{p}<.02)$. Experimental ss with basolateral placements made significantly (p<.01) more approach-withdrawals than those with corticomedial placements (Fig. 4). Again the only significant monotonic trends were those of the control groups (p<.01).. Iatency

The $\underline{S} s$ in the experimental group were slower than either the stimulated controls (p<.01) or the normal controls (p<.01) in their first contact with the water spout (Fig. 5). The difference between the corticomedial and basolateral placements (Fig. 6) was highly significant (p<.001). The only significant trends were those of the control groups: stimulated controls (p<.001); operated controls (p<.05); normal controls $(p<.01)$

Time Spent Frozen

Normal control $\underline{S} s$ spent more time frozen than the experimental ss $(p<.05)$. There were no other differences 
between controls and experimentals on this measure. As shown in Fig. 7, basolateral placements spent more time frozen than the corticomedial group ( $p<001)$. The only significant monotonic trend was that of the normal control group ( $p<.001)$. It is clear that time frozen is not as sensitive a measure as mouth shocks, approach-withdrawals or latency of first contact.

Defecations

There were no significant differences between experimental $\underline{\mathbf{S}} \mathbf{s}$ and control $\underline{\mathbf{s}} \mathbf{s}$ on any day nor were there any significant trends.

\section{Histology}

Microscopic examination of the histology of the stimulated $\underline{S} s$ revealed that all the placements fell into three groups: basolateral amygdala $(n=5)$, corticomedial amygdala $(n=5)$, and stimulated controls $(n=8)$, that is, placements which missed either of the two former groups of nuclei (Figs. 8-I1).

\section{Discussion}

The results of this experiment clearly indicate that noncontingent, continuous stimulation of the amygdala, particularly the basolateral nucleus, impairs the acquisition 
of a passive avoidance response. There are several possible interpretations of these data that should be considered.

The stimulation may have increased the thirst drive of the experimental Ss. Although there is considerable evidence that amygdaloid lesions and stimulation affect food intake (Goddard, 1963), there is no evidence available which suggests that the amygdala has a role in the mechanism of thirst. secondly, it was reported above that the latencies of the basolateral $\underline{S} s$. the group which accepted the most mouth shocks and made the most approaches to the water spout, were the longest. If these animals were thirstier than the others, one would expect their latencies to be shorter or at least equal to the other $\underline{s}$.

The results could be attributed to a deficit in learning ability caused by the stimulation. The results of this and other experiments suggest that this hypothesis is untenable. It can be observed in Fig. 1, that the experimental Ss accepted significantly fewer (p<.002) mouth shocks on the second day than they did on the first day. There was no difference between the experimentals 
and controls on this day. Also it was observed that the experimental $\underline{s} s$ typically did not drink immediately from the water spout when placed in the test chamber, but instead went to the spout and made a series of approachwithdrawals before making the first contact with the spout. This behavior, although observed in control $\underline{S}$ also, was more characteristic of the experimental ss and is reflected in their longer latencies (Fig. 5). These data indicate that they had learned that the spout was "hot". Secondly, Goddard (1963), using a similar but less intense stimulation of the amygdala, found that although the animals were impaired in the acquisition of a complex avoidance response, they were not impaired in learning a simple active avoidance response.

Another possible interpretation of the data is that the stimulation was either rewarding or noxious and that it was the affective component of the stimulation which impaired the acquisition of the passive avoidance response. There is considerable evidence opposed to this possibility. Olds and olds (1961) reported that noncontingent rewarding stimulation interferes primarily with approach learning. The present experiment involves 
avoidance learning. Goddard (1963) found that the type of stimulation used in this study had no effect on extinction rates in bar-pressing for food, indicating that the stimulation had no rewarding properties. It is also possible that the stimulation may have been noxious. Steiner and D'Amato (1964) reported that when thirsty rats were given a choice between two levers, one producing water alone and the other, water plus electrical stimulation of the amygdala, low current intensities (below $40 \mu \mathrm{A}$ ) were clearly aversive. However, the number of subjects in this study was very small $(n=3)$ and the stimulation was contingent upon the lever press and not continuous. However, Olds and Olds (1961) reported that noncontingent stimulation of areas which yield negative reinforcement produced no impairment in learning. Consequently even if the stimulation used in this experiment were noxious, an impairment in the passive avoidance response would not be expected.

Explanations of the data in terms of a change in emotionality or an increase in general activity are also inadequate. The stimulation did not affect the ease of handling of the $\underline{S}$, and as reported above there were no significant differences in the number of defecations. 
Similarly the results cannot be attributed to an increase in general activity. The normal controls were the only animals to differ significantly in time spent frozen from any of the other animals. Secondly the animals that accepted the most mouth shocks; the basolateral group, spent more time frozen than any of the other animals except the normal controls.

The hypothesis that seems most plausible is that the amygdala is involved in response inhibition, and that noncontingent stimulation of the amygdala disrupts this function. This hypothesis has been used by Mccleary (1961), Kaada, Rasmussen and Kviem (1962) and Kasper (1963, 1964) in their interpretation of the deficit produced by septal lesions and noncontingent septal stimulation in the acquisition of the passive avoidance response. Anatomical evidence (Gloor, 1960) suggests that the amygdala and septal area may be part of a circuit mediating response inhibition. Furthermore, the evidence reviewed in the introduction and the data reported in this experiment strongly suggest that the amygdala plays a significant role in behavioral inhibition. 
The question of the effect of noncontingent continuous stimulation on a neural structure still remains. The similarity of effects obtained with septal lesions (McCleary, 1961; Kaada, Rasmussen and Kveim, 1962) and noncontingent septal stimulation (Kasper, 1963, 1964) has led to the suggestion (Goddard, 1963) that this type of stimulation produces its effect by causing a "functional lesion." That is, the stimulation disrupts the otherwise normal flow of impulses through the amygdala. This disruption is reflected behaviorally in the persistence of response tendencies that are no longer adaptive. If this were the case, one would expect to get similar results with amygdaloid lesions as have been reported here with noncontingent stimulation. This question remains to be answered since the methodology of the only study available (Horvath, 1963) severely restricts any conclusions which can be drawn from the data reported.

\author{
Summary \\ Noncontingent, continuous stimulation of the
} amygdala in the rat, particularly the basolateral nucleus, impairs the acquisition of a passive avoidance response (PAR). 
Experimental $\underline{S} s(n=10)$ approached and accepted more mouth shocks from an electrified water spout than control s s ( $n=24)$. Similar impairments in the acquisition of the PAR are obtained with septal lesions and noncontingent septal stimulation. In light of anatomical evidence it is reasonable to suggest that the amygdala and septal area are part of a circuit mediating response inhibition. It is also suggested that noncontingent stimulation disrupts the normal adaptive functioning of the amygdala in its mediation of response inhibition. 
Brutkowski, S., Fonberg, E. \& Mempel, E. Alimentary type II (instrumental) conditioned reflexes in amygdala dogs. Acta. bio1. Exp., 1960, 20, 263-271.

deGroot, J. The rat forebrain in stereotaxic coordinates. Verh. Kon. Ned. Akad. Wet., B. Naturkunde, 1959, 52, 1-40.

Egger, M.D., \& Flynn, J.P. Amygdaloid suppression of hypothalamically elicited attack behavior. Science, $1962,136,43-44$.

Egger, M.D., \& Flynn, J.P. Effects of electrical stimulation of the amygdala on hypothalamically elicited attack behavior in cats. J. Neurophysiol., 1963, 26, 705-720 .

Ferguson, G.A. Statistical analysis in psychology and education. Toronto: McGraw-Hill, 1959.

Ferguson, G.A. Nonparametric trend analysis. Unpublished manuscript. McGill University, 1962.

Fonberg, Elzbieta. The inhibitory role of amygdala stimulation. Acta. biol. Exp., 1963, 23, $171-180$ 
Fonberg, E., \& Delgado, J.M.R. Avoidance and alimentary reactions during amygdala stimulation. I. Neurophysiol., 1961, 24, 651-654.

Gloor, P. Amygdala. In J. Field (Ed). Handbook of physiology. Vol. 2. Washington, D.C.: American Physiological Society, 1960. $1395-1420$.

Goddard, G. The effect of amygdaloid stimulation on learning in the rat. Unpublished Doctoral Dissertation, McGill University, 1963. Horvath. F. E. Effects of basolateral amygdalectomy on three types of avoidance behavior in cats. J. comp. physiol. Psychol., 1963, 56, 380-389.

Kaada, B.R., Rasmussen, E.W.\& \& Kviem, O. Impaired acquisition of passive avoidance by subcallosal, septal, hypothalamic and insular lesions in rats. J. comp. physiol. Psychol.; 1962, 55, 661-670.

Kasper. Phyllis M. Attenuation of passive avoidance by continuous septal stimulation. Unpublished Master's thesis, McGill University. 1963. 
Kasper, Phyllis M. Attenuation of passive avoidance by continuous septal stimulation. Psychon. Sci., 1964, (in press).

Kellicutt, M.H., \& Schwartzbaum, J.S. Formation of a conditioned emotional response (CER) following lesions of the amygdaloid complex in rats. Psychol. Rep., 1963, 12, 351-358.

McCleary, R. Response specificity in the behavioral effects of limbic system lesions in the cat. J. comp. physiol. Psycho1., 1961, 54, 605-613.

Olds, M.E. \& Olds, J. Emotional and associative mechanisms in rat brain. J. comp. physiol. Psycho1., 1961, 54, 120-126.

Schwartzbaum, J.S., Thompson, J.B.. \& Kellicutt, M.H. Auditory frequency discrimination and generalization following lesions of the amygdaloid area in rats. J. comp. physiol. Psychol., 1964, 57, 257-266.

Steiner, S., \& D'Amato, M.R. Rewarding and aversive effects of amygdaloid self-stimulation as a function of current intensity. Psychon. Sci., $1964,1,27-28$ 


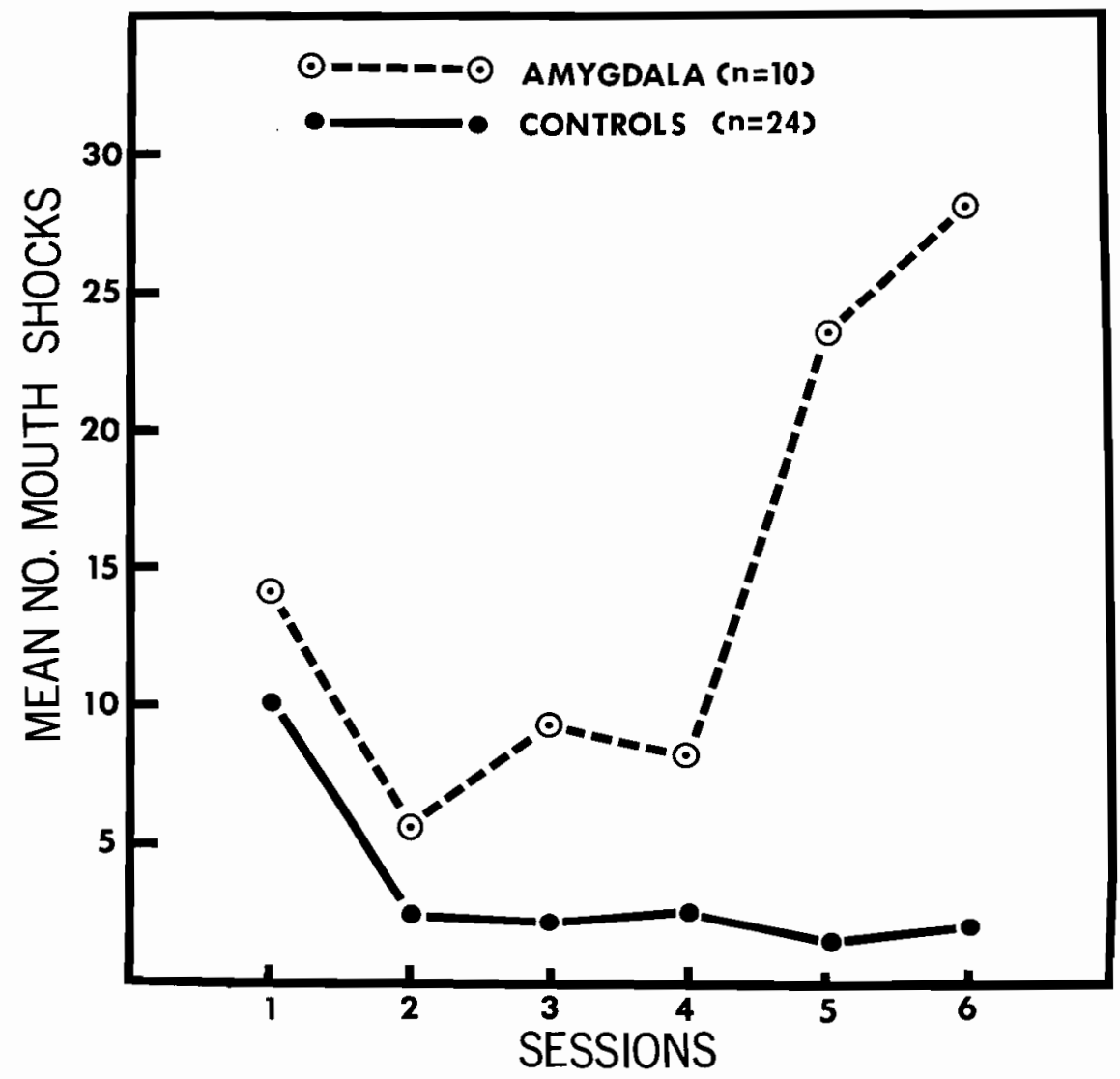

Fig. 1. Mean number of mouth shocks accepted by experimental and control ss during successive test sessions. 


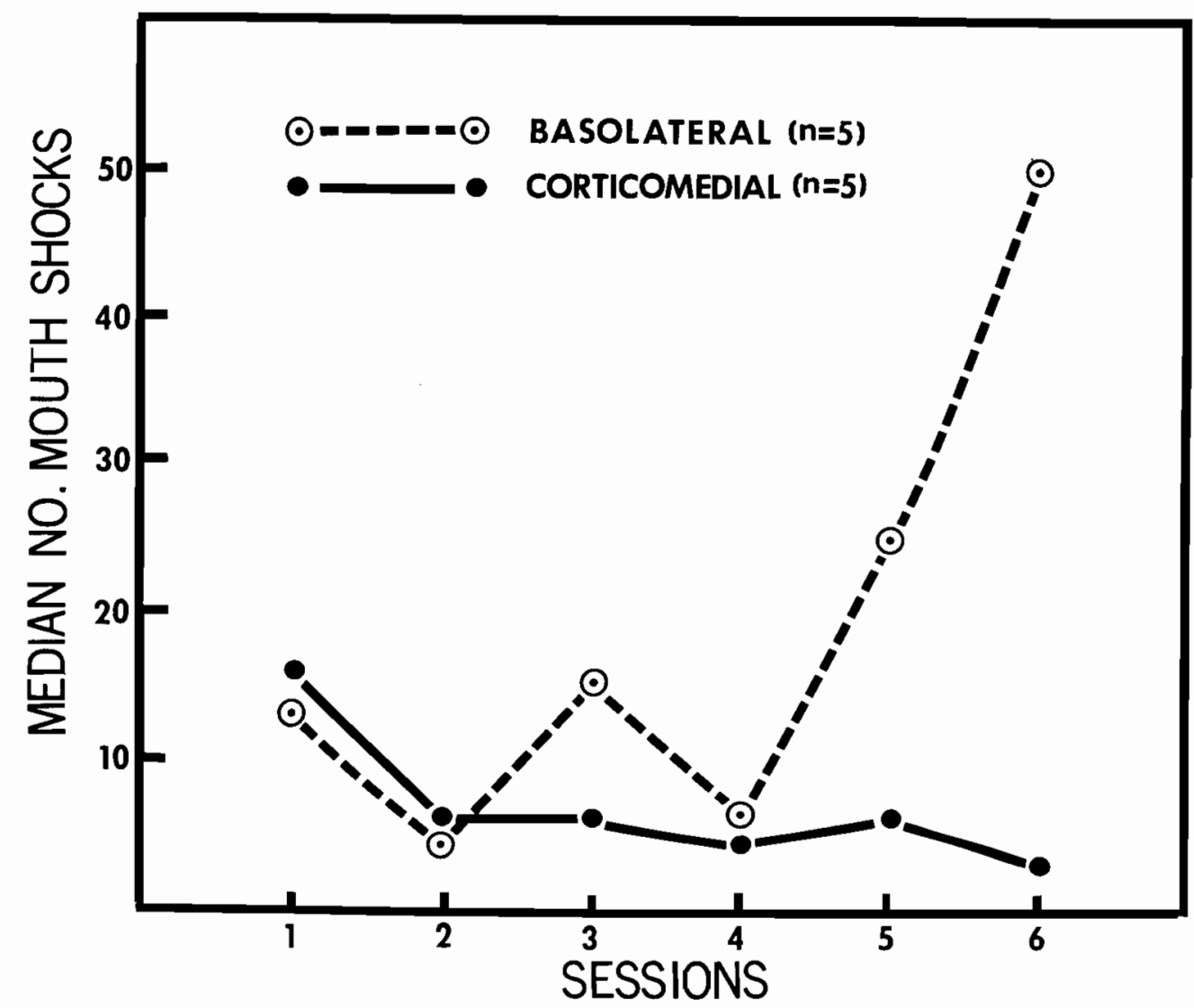

Fig. 2. Median number of mouth shocks accepted by basolateral and corticomedial ss during successive test sessions. 


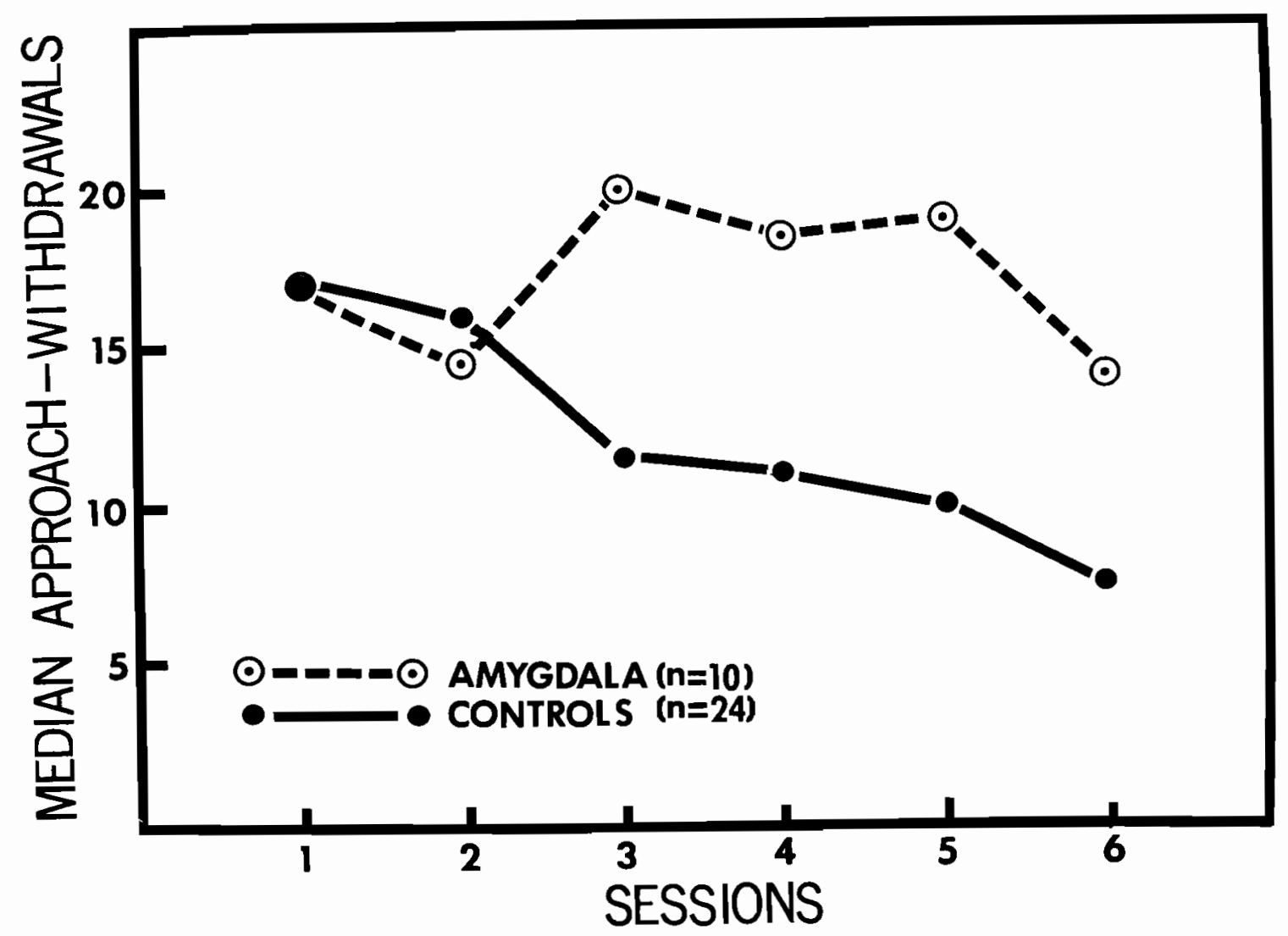

Fig. 3. Median number of approach-withdrawal responses made by experimental and control $\underline{\text { ss }}$ during successive test sessions. 


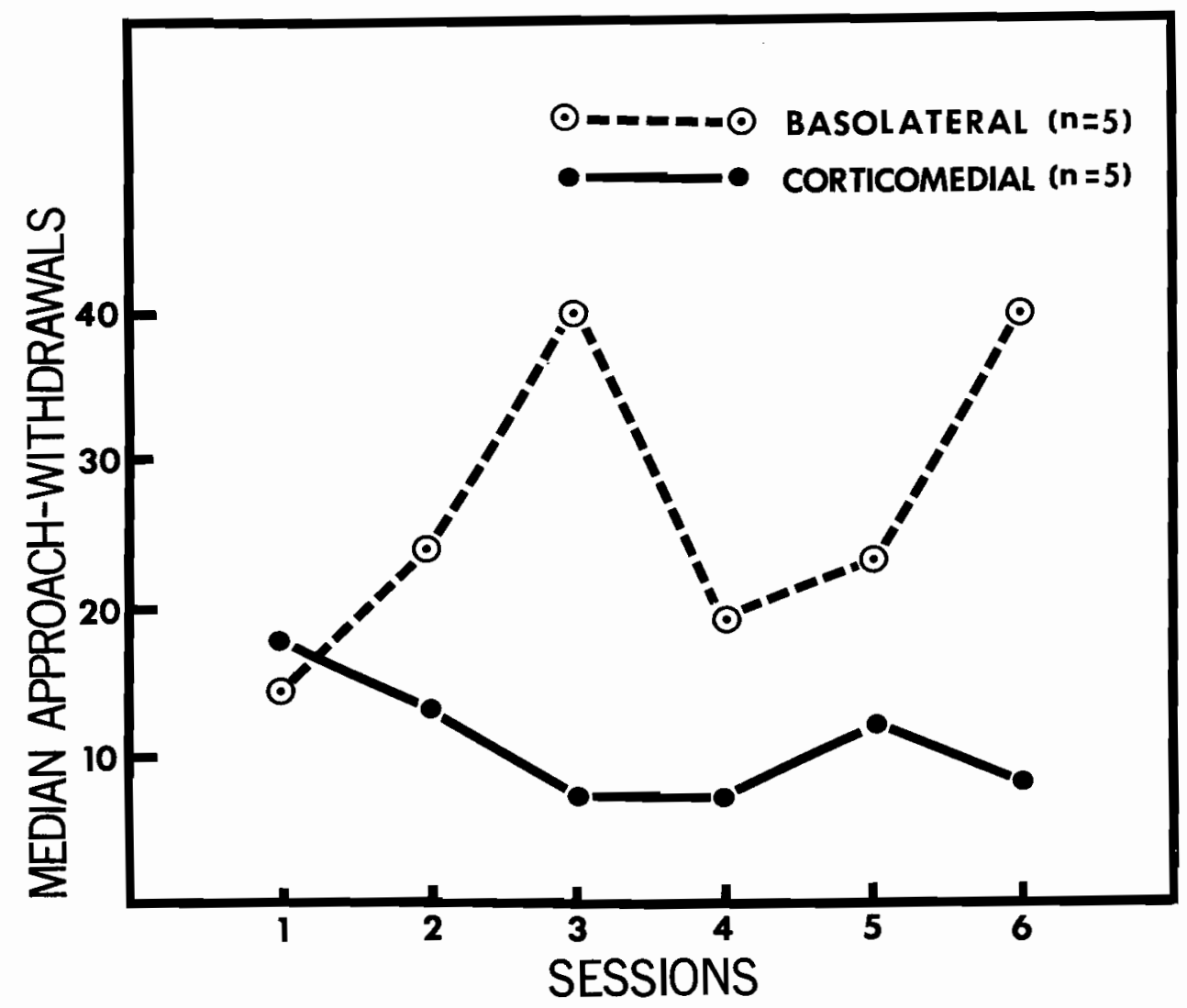

Fig. 4. Median number of approach-withdrawal responses made by basolateral and corticomedial $\underline{\text { ss }}$ during successive test sessions. 


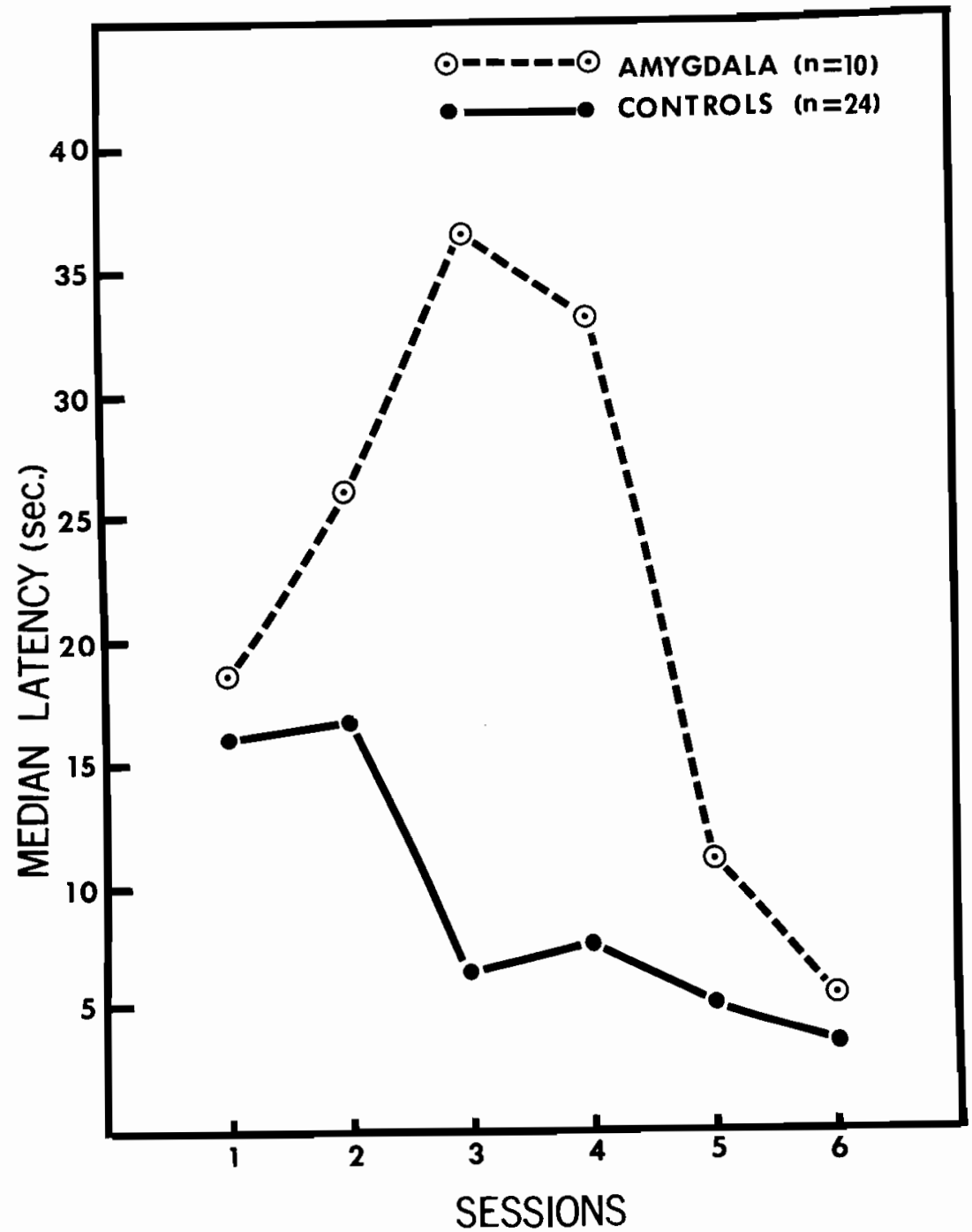

Fig. 5. Median latency of first daily contact with water spout of experimental and control ss at the beginning of each test session. 


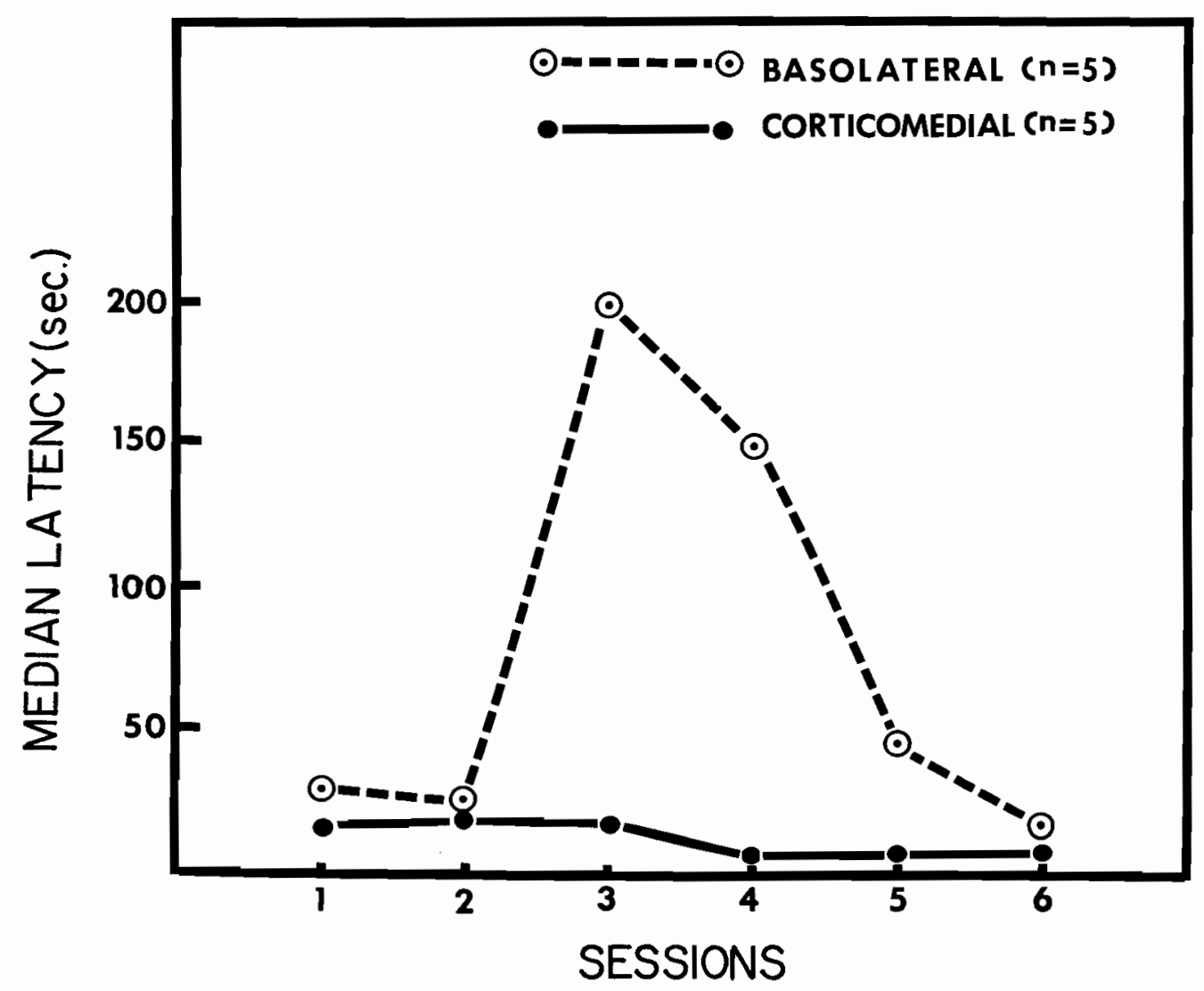

Fig. 6. Median latency of first daily contact with the water spout of basolateral and coticomedial $\underline{S} s$ at the beginning of each test session. 


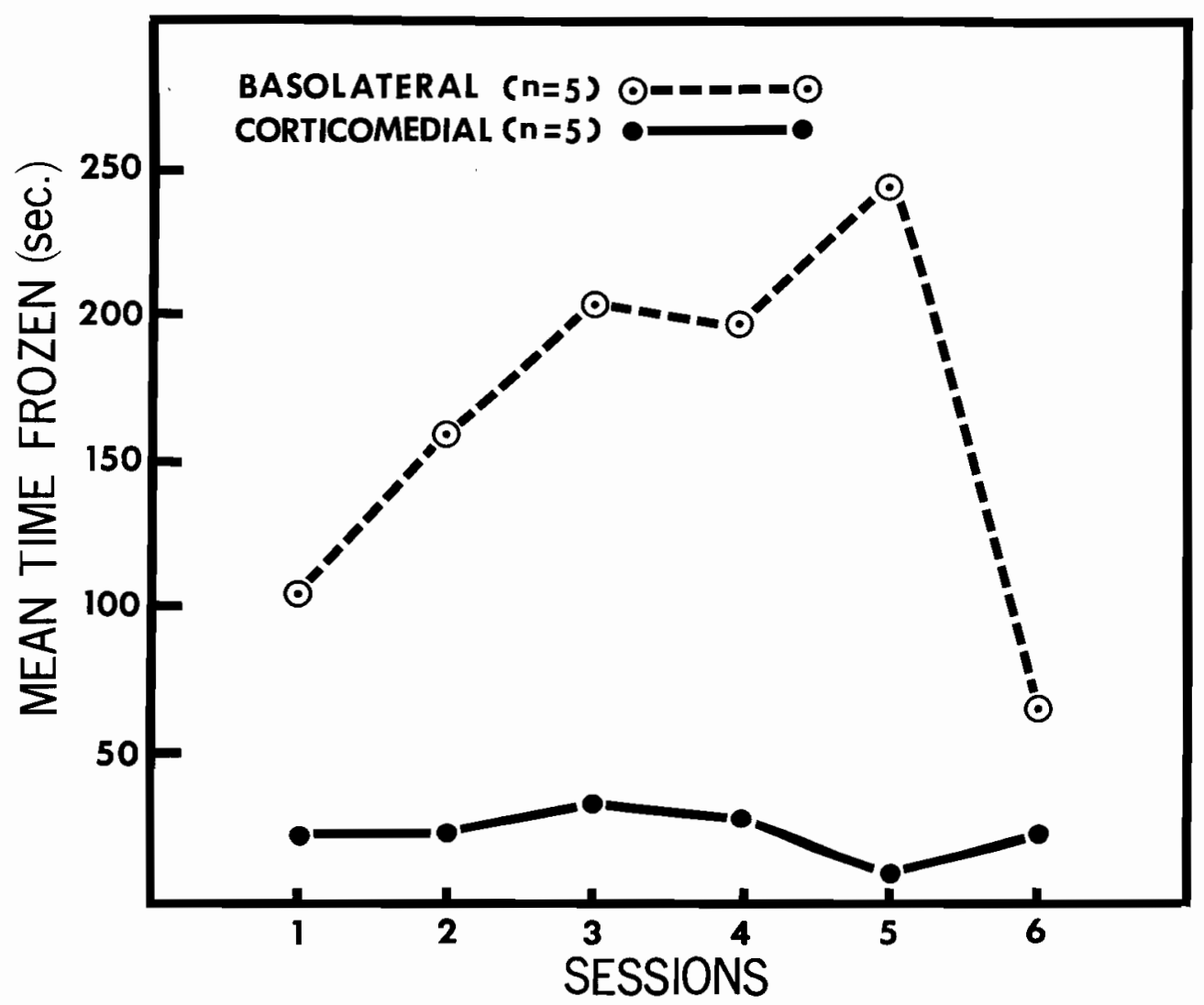

Fig. 7. Mean total amount of time spent frozen by

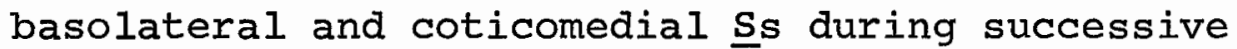
test sessions. 


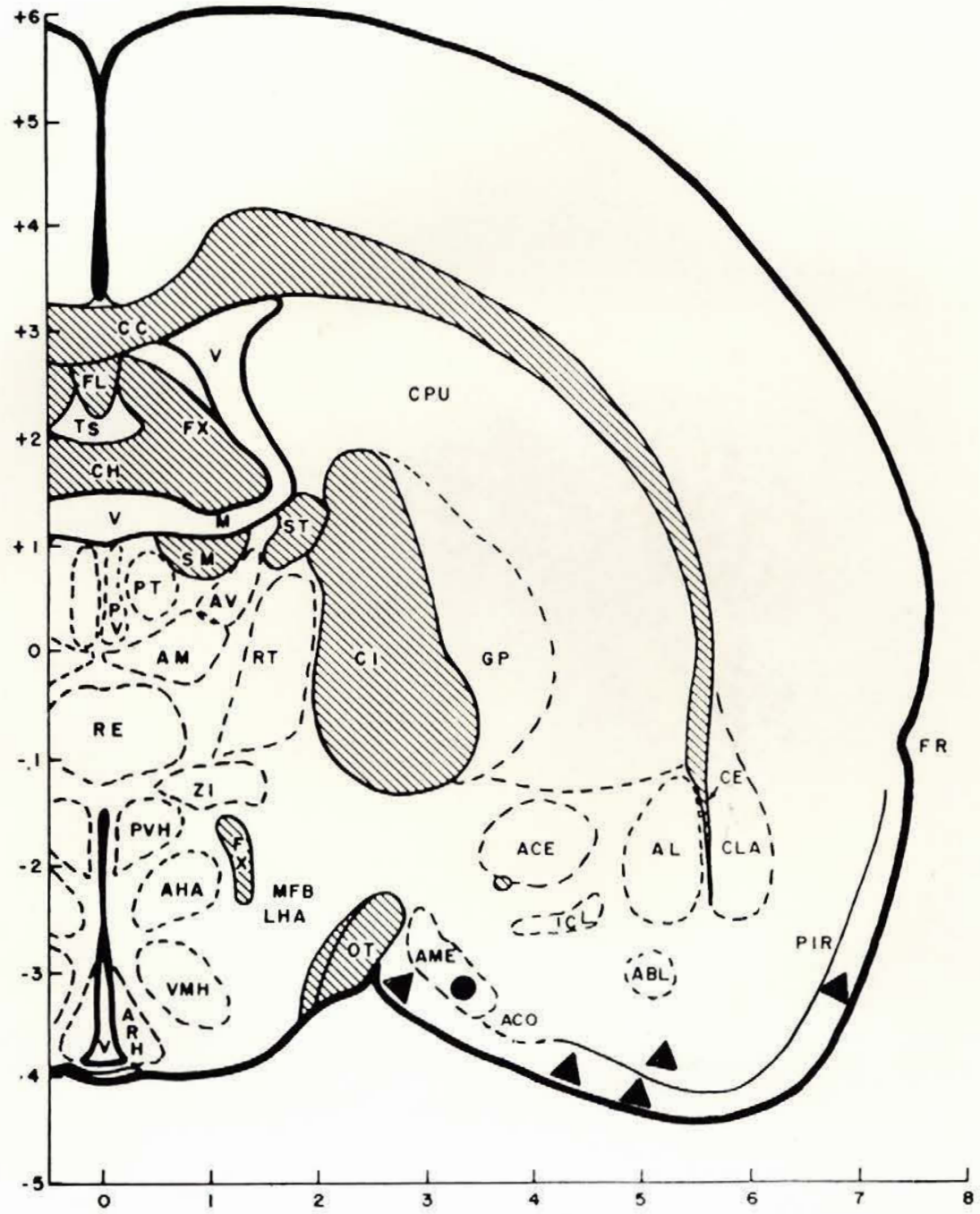

Fig. 8. Anatomical location of electrodes in the amygdala and surrounding structures. Dots indicate experimental $\underline{S}$ s and triangles indicate stimulated controls. Sections are from deGroot (1959) and 
are arranged in an anterior-to-posterior order. Abbreviations: ABL, amygdaloid basolateral nucleus; ACE, amygdaloid central nucleus; ACO, amygdaloid cortical nucleus; $A L$, amygdaloid lateral nucleus; AME, amygdaloid medial nucleus; CE, external capsule; CLA, claustrum; OT, optic tract; PIR, pyriform cortex; ST, stria terminalis; TZ, zona transitionalis; V, lateral ventricle. 


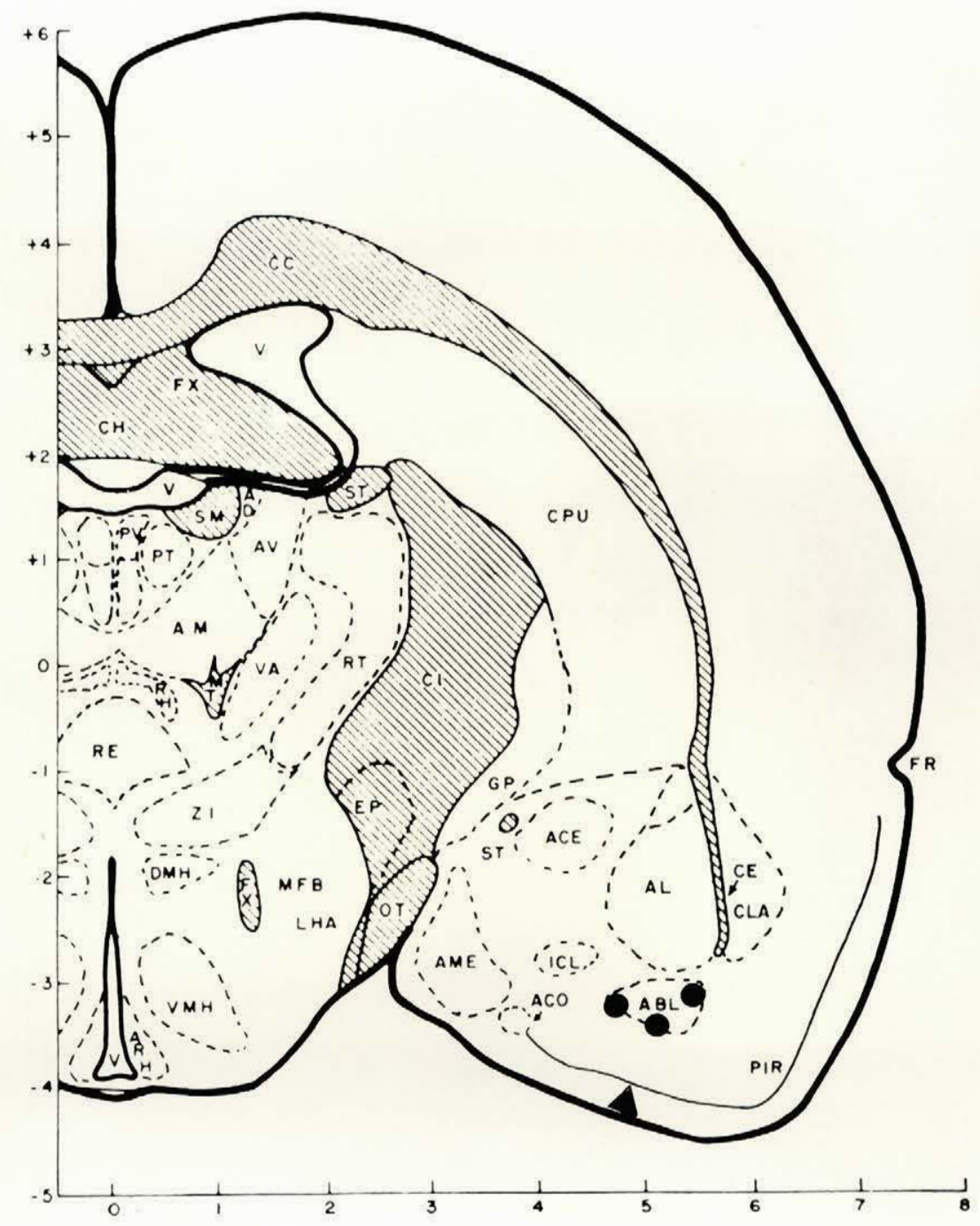

Fig. 9. Anatomical location of electrodes in the amygdala and surrounding structures. Dots indicate experimental $\underline{\text { Ss }}$ and triangles indicate stimulated controls. See Fig. 8 for explanation of abbreviations. 


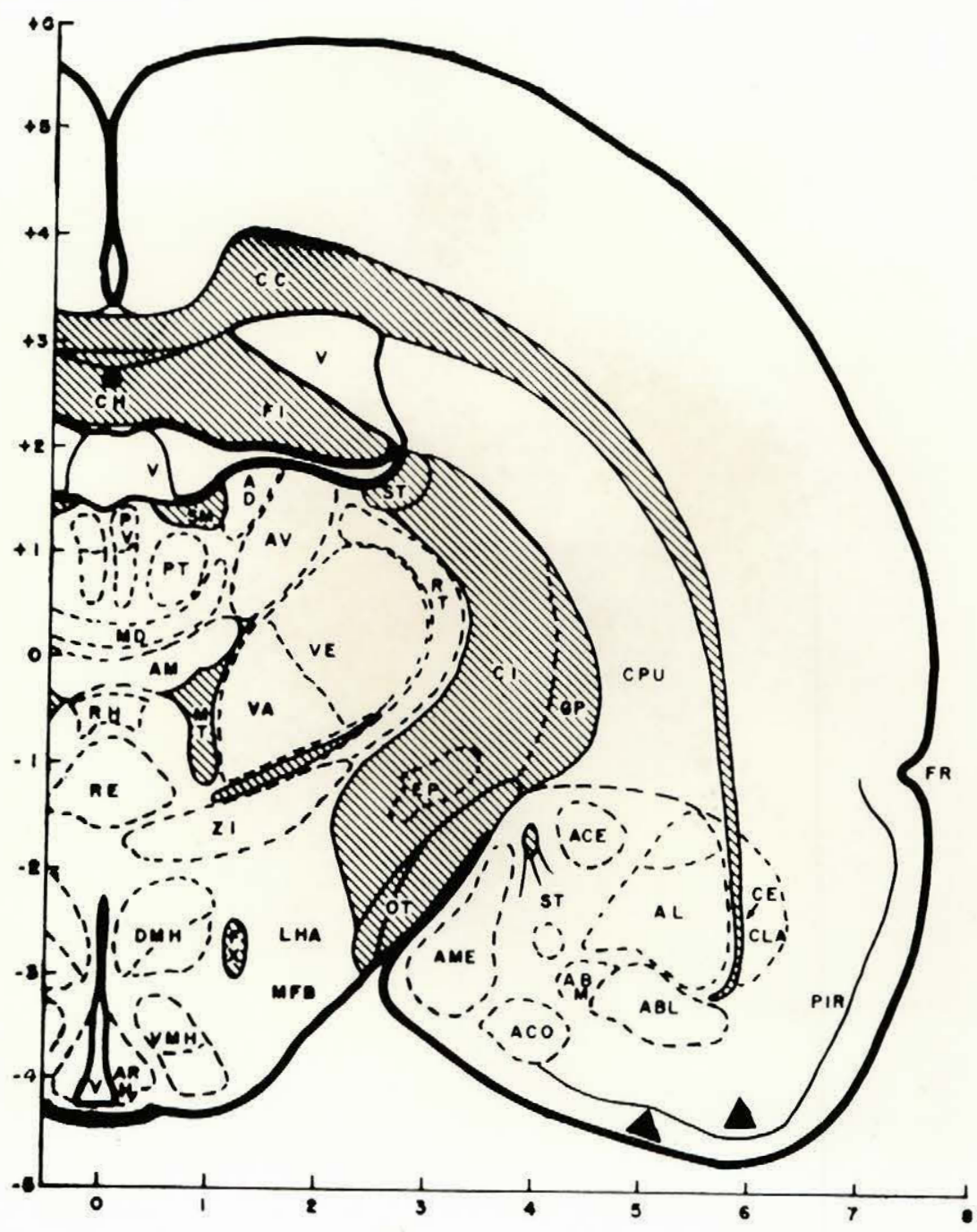

Fig. 10. Anatomical location of electrodes in the amygdala and surrounding structures. Dots indicate experimental $\underline{\text { SS }}$ and triangles indicate stimulated controls. See Fig. 8 for explanation of abbreviations. 


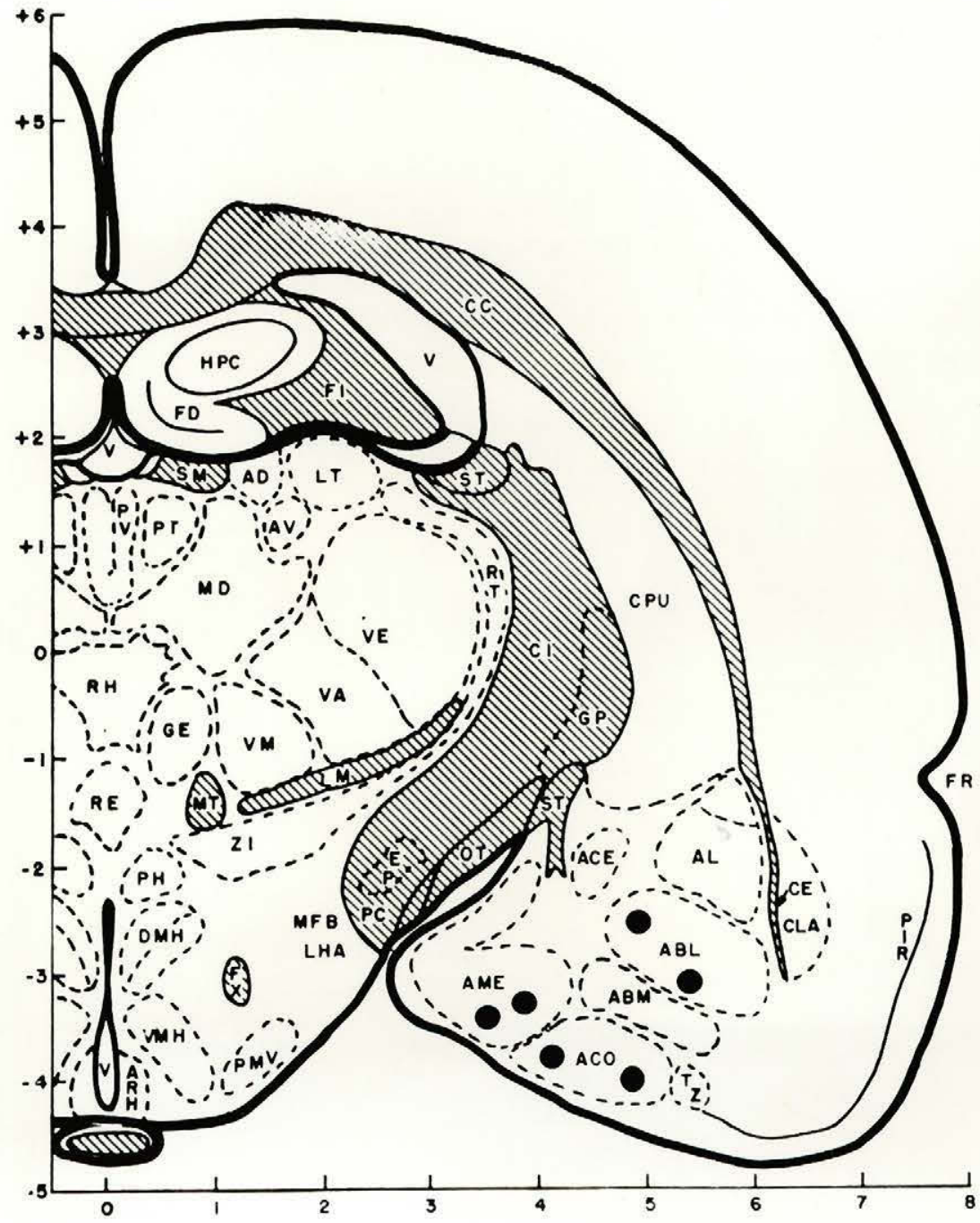

Fig. 11. Anatomical location of electrodes in the amygdala and surrounding structures. Dots indicate experimental $\underline{S} s$ and triangles indicate stimulated controls. See Fig. 8 for explanation of abbreviations. 


\section{Table 1}

\section{Behavioral differences between experimental and control groups}

Significance of difference from amygdala group

Stimulated controls Operated controls Normal controls

Mouth Shocks

Latency

Feces

Time Frozen

$$
<.001
$$

N.S.

$<.01$

N.S.

N.S.
$<.001$

$<.05$

N.S.

N.S.

N.S. 